\title{
Quando os vegetais são demais: um caso de carotenodermia
}

Raquel Xavier Martins Costa, ${ }^{1}$ Hugo Manuel de Azevedo Lourenço Lopes ${ }^{2}$

\section{RESUMO}

Introdução: Os carotenos são um pigmento ubíquo na natureza, inicialmente identificado na cenoura (do inglês carrot). Do pigmento ingerido, $10 \%$ é absorvido inalterado e transportado ao fígado, sendo o restante convertido, no próprio intestino, em vitamina A. O excesso é excretado pelo cólon e epiderme. Contudo, quando elevado, o estrato córneo, lipossolúvel, reabsorve e acumula-o, conferindo uma coloração amarelada à pele. As crianças, quer pela imaturidade dos sistemas de conversão enzimáticos, quer pela dieta e modo de preparação dos alimentos, estão mais susceptíveis a apresentar níveis elevados de carotenos no sangue (carotenemia) e na pele (carotenodermia).

Descrição do caso: G.A.F., do sexo masculino, é trazido à consulta de vigilância dos nove meses. Apresenta coloração amarelada nas palmas das mãos e plantas dos pés. Sem outras queixas ou intercorrências de registo. Ao exame objetivo apresenta escleras e mucosa oral de coloração normal. Mãe refere consumo excessivo de cenoura e batata-doce na sopa. É colocada a hipótese de carotenodermia e explicada aos pais a benignidade da situação.

Comentário: Apesar de outras causas, além da dieta, serem extremamente raras em crianças, existe associação entre carotenemia e várias patologias, nomeadamente diabetes mellitus, hipotiroidismo, anorexia nervosa e discinésia biliar, que terão de ser investigadas caso não se resolva o quadro com as alterações dietéticas. Os carotenos estão presentes nos alimentos como cristais encapsulados. Triturá-los rompe as membranas celulares e torna-os mais disponíveis para absorção, tornando a alimentação infantil à base de purés mais propensa ao seu desenvolvimento. Independentemente da cor, vários alimentos (e.g., brócolos e feijão verde) possuem níveis elevados de carotenos e devem ser tidos em conta na entrevista clínica.

Não obstante a benignidade do quadro, a sua correta identificação é de extrema importância por forma a evitar a, não tão rara, confusão diagnóstica com icterícia e subsequente estudo desnecessário e dispendioso.

Palavras-chave: Caroteno; $15^{\prime} \beta$ caroteno dioxigenase.

\section{INTRODUÇÃO}

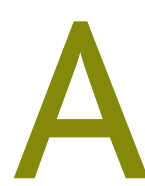

associação entre coloração amarela da pele e crianças que ingerem cenouras é conhecida desde há muito tempo. É, contudo, impressionante a escassez de casos relatados e de informação disponível sobre o tema.

Os carotenos são um pigmento de origem vegetal. Sendo o Homem incapaz de os sintetizar, é obtido a partir dos alimentos. ${ }^{1}$ Foi identificado pela primeira vez na cenoura (do inglês carrot), atribuindo-lhe o nome, mas encontra-se presente em diversas frutas e vegetais, sendo o responsável pela sua coloração. ${ }^{2} \mathrm{O}$ pig-

1. Médica Interna de Medicina Geral e Familiar. USF Vitrius.

2. Médico Assistente de Medicina Geral e Familiar, USF Marquês, Aces Pinhal Litoral. mento é um eficiente percursor da vitamina A, sendo o $\beta$-caroteno a pró-vitamina mais efetiva. É convertido em duas moléculas de vitamina A pela $15 \beta$-caroteno dioxigenase ao nível das células hepáticas e da mucosa intestinal. $^{3}$

Cerca de $10 \%$ dos carotenos ingeridos na alimentação são reabsorvidos inalterados para a circulação portal, ${ }^{4}$ sendo grande parte convertida, no próprio intestino, sobretudo a nível duodenal, em vitamina A. ${ }^{2} \mathrm{O}$ excesso é excretado pelo cólon e pela epiderme. Quando os mecanismos de excreção se esgotam, o estrato córneo, camada lipossolúvel da epiderme, reabsorve o excesso e acumula-o. Isto ocorre sobretudo nas zonas da pele mais abundantes em glândulas sudoríparas, como são as palmas das mãos, as plantas dos pés e o sulco 
nasolabial. ${ }^{2,5}$ Quando os níveis de carotenos no sangue atingem valores superiores a 150 / dL é considerada carotenemia. Se atingido um valor três a quatro vezes superior, a acumulação na pele torna-se visível e designa-se por carotenodermia. ${ }^{6}$ Trata-se de uma situação benigna que afeta sobretudo crianças. As consultas de vigilância de saúde infantil são uma boa oportunidade de identificar estes casos, fazer o aconselhamento dietético adequado e, acima de tudo, tranquilizar os pais/cuidadores.

O caso apresentado evidencia um dos papéis mais importantes do médico de família, que passa por distinguir a doença da não doença. Assumi-lo como tal não se trata de uma atitude passiva, mas de uma atitude ativa que opta pela vigilância clínica e recusa a investigação diagnóstica. Esta, quando desadequada, acarreta preocupação e ansiedade desnecessárias e eventualmente danos evitáveis. A única forma de tomar esta posição com segurança passa pela tomada de conhecimento destes casos; daí, a relevância deste relato.

\section{DESCRIÇÃO DO CASO}

\section{Identificação}

Criança do sexo masculino com nove meses de idade, fruto de uma gravidez de 39 semanas mais um dia, vigiada, de mãe Rh negativa de 38 anos de idade, sob aleitamento materno exclusivo até aos seis meses. Estatura, peso e perímetro cefálico no percentil 15-50. A fazer vitamina $\mathrm{D}(0,5 \mathrm{mg} / \mathrm{mL}$ id). Como antecedentes pessoais apenas uma dermatite das fraldas aos 11 dias de vida. Foi medicado com clotrimazol creme e suspensão de óxido de zinco, que resolveu. Não se registaram outras intercorrências.

\section{Consulta de vigilância dos 9 meses}

É trazido pelos pais à consulta de vigilância dos nove meses a 20/03/2017. À observação apresentava coloração amarela, mais evidente nas palmas das mãos, plantas dos pés, nariz e sulco nasolabial (Figura 1). Quando interrogada acerca da alimentação da criança, a mãe referiu consumo aumentado de cenoura e batata-doce na sopa nas últimas semanas. Ao restante exame objetivo não apresentava alterações, encontrando-se as escleras e a mucosa oral de coloração normal. Os dados da história e do exame objetivo levantaram a hipótese diagnóstica de carotenodermia, que foi então assumida. Es-

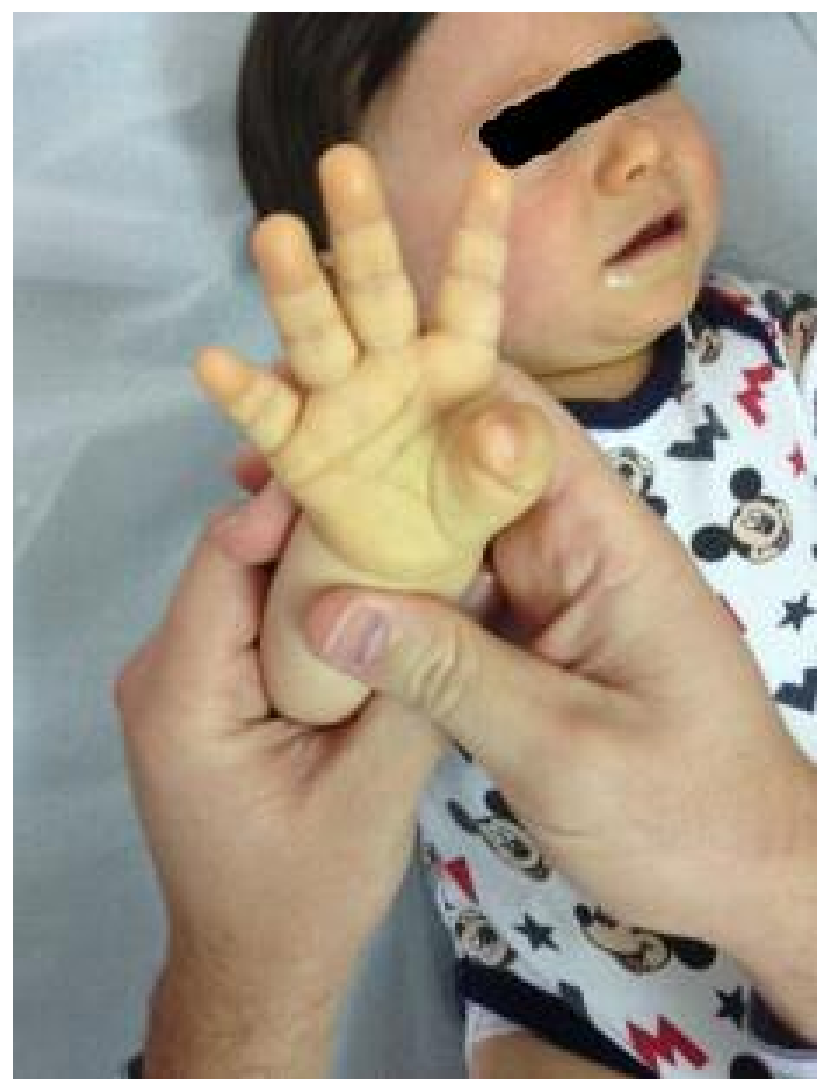

Figura 1. Coloração amarela da palma da mão e sulco nasolabial.

clareceu-se aos pais a benignidade da situação e aconselhou-se a redução da quantidade de cenoura e batata-doce na sopa. Foi programada reavaliação para a consulta de vigilância dos 12 meses.

\section{Consulta de vigilância dos 12 meses}

No dia 26/06/2017, G.A.F veio à consulta de vigilância dos 12 meses onde se pôde confirmar o desaparecimento das alterações da cor das palmas das mãos, plantas dos pés e sulco nasolabial, tendo os pais cumprido as alterações na dieta. À data da consulta não apresentava queixas de novo, o exame objetivo não tinha alterações e foram feitos os ensinos adequados à idade do utente.

\section{COMENTÁRIO}

As crianças estão mais suscetíveis que os adultos ao excesso de carotenos no sangue por vários motivos. Em primeiro lugar, a alimentação infantil, até ao primeiro 


\begin{tabular}{|l|l|l|}
\hline \multicolumn{2}{|l|}{ QUADRO I. Alimentos ricos em carotenos } \\
\hline Vegetais & Fruta & Outros \\
\hline Cenoura & Damasco & Manteiga \\
Abóbora & Melão & Ovos \\
Espargos & Manga & Leite (++Materno) \\
Beterraba & Papaia & Óleo de palma \\
Brócolos & Laranja & \\
Feijão-verde & Pêssego & \\
Quiabo & Ameixa & \\
Ervilhas & & \\
Espinafres & & \\
Batata-doce & & \\
\hline
\end{tabular}

ano de vida, é rica em fruta e vegetais, alimentos ricos em carotenos. Erradamente pode-se assumir que apenas os alimentos de cor laranja ou amarela são ricos no pigmento. ${ }^{1}$ Importa salientar que, independentemente da cor, várias frutas e legumes, assim como a manteiga, o ovo e o leite, sobretudo o materno, ${ }^{4}$ são ricos em carotenos (Quadro I). Muitos legumes e frutas verdes contêm até quantidades mais elevadas de carotenos comparativamente às amarelas e laranjas. Nestes, porém, a cor amarela do caroteno está mascarada pela cor verde da clorofila. ${ }^{1}$

Em segundo lugar, estes alimentos são ingeridos maioritariamente, se não em exclusivo, na forma de purés e sopas. Os carotenos encontram-se presentes nos alimentos na forma de cristais encapsulados. Esmagar ou triturá-los rompe as membranas celulares e os cristais são libertados, ficando mais disponíveis para a absorção. ${ }^{1-2,5}$ Quanto mais triturados os alimentos na dieta das crianças, mais altos os níveis de carotenos no sangue que elas apresentam. ${ }^{7}$ Por último, os sistemas de conversão enzimáticos, nomeadamente a $15^{\prime} \beta \mathrm{ca}$ roteno dioxigenase, encontram-se ainda em maturação e, portanto, o seu funcionamento não ocorre em pleno, levando a um atraso na conversão dos carotenos em vitamina A.

Ainda assim, entre crianças com o mesmo tipo de alimentação, umas são mais propensas a desenvolver o quadro que outras. Ainda não é clara a razão pela qual

\section{QUADRO II. Associações com carotinemia}

Associações com carotenemia

Dieta

Hipotiroidismo

Diabetes Mellitus

Anorexia Nervosa

Doença Hepática

Discinésia Biliar

Erros inatos do metabolismo

isto acontece. Entram em linha de conta a idade e o peso. Casos de carotenodermia parecem mais frequentes em crianças mais novas e com menos peso, ${ }^{7} \mathrm{o}$ que poderá estar relacionado com uma menor área de distribuição e aumento da concentração, mas carecem estudos que o comprovem. Existe também considerável variabilidade interindividual nos níveis de lipoproteínas no sangue (transportadoras dos carotenos), dos ácidos biliares e lípase pancreática ${ }^{2}$ (necessárias para a absorção) e ainda uma atividade variável das enzimas

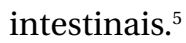

Outras causas, além da dieta, são extremamente raras em crianças. ${ }^{1}$ A redução da dieta dos alimentos ricos em carotenos que estão a ser consumidos em excesso deve levar ao desaparecimento das alterações na pele num período de duas a seis semanas, ${ }^{2,4}$ sendo que no sangue os valores normalizam dentro de uma semana, aproximadamente. ${ }^{4}$ Caso tal não se verifique, outras causas de carotenodermia devem ser consideradas (Quadro II).

Existe associação entre algumas patologias e níveis de carotenos aumentados no sangue. O mecanismo por detrás desta associação resulta de uma diminuição da conversão dos carotenos em vitamina $\mathrm{A}$, levando à sua acumulação e excreção aumentadas; ocorre na diabetes mellitus, discinésia biliar, ${ }^{6}$ doença hepática, hipotiroidismo e anorexia nervosa. Estas patologias cursam com o aumento das lipoproteínas no sangue. Sendo estas as principais transportadoras dos carotenos, a sua conversão é prejudicada por estarem ligados às suas moléculas de transporte em vez de livres para absorção. ${ }^{2,5-6}$ Também na diabetes, a conversão dos $\beta$-caro- 
tenos em vitamina A ao nível da mucosa intestinal parece estar prejudicada. ${ }^{5} \mathrm{Na}$ doença hepática, a conversão está prejudicada ao nível das células hepáticas, ${ }^{4}$ assim como na patologia intestinal em que a acumulação dos carotenos pode resultar da diminuição da sua conversão pelo caroteno dioxigenase ao nível da mucosa danificada. ${ }^{3}$ As hormonas tiroideias aceleram a conversão dos carotenos em vitamina $A,{ }^{3,5}$ pelo que no hipotiroidismo esta se encontra prejudicada. Existem também associações entre carotenemia e anorexia nervosa, não estando o mecanismo completamente esclarecido. Pode resultar de padrões de alimentação bizar$\operatorname{ros}^{2}$ ou de necessidades diminuídas na presença de ingestão normal ou mesmo pela hipercolesterolemia que estes doentes apresentam. ${ }^{5}$

Nos primeiros anos de vida importa sobretudo excluir os erros inatos do metabolismo. ${ }^{2}$ Devem ser considerados quando não existe história de consumo excessivo de alimentos ricos em carotenos ou quando as alterações na pele se prolongam além do tempo normal de resolução. Maioritariamente são por deficiência total ou parcial da $15^{\prime} \beta$ caroteno dioxigenase $e^{5}$ e deve ser um diagnóstico de exclusão. Por ter um custo muito elevado e não alterar a conduta terapêutica, a confirmação diagnóstica não é recomendada. ${ }^{3}$ Há também descrição de um caso de carotenodermia por níveis persistentemente baixos da proteína de ligação ao retinol. $^{5}$

Não existe atualmente evidência que outras alterações dietéticas, além da redução dos alimentos implicados, sejam necessárias. A tranquilização dos pais é a única conduta que deve ser tomada. ${ }^{1-2} \mathrm{~A}$ resolução espontânea do quadro em crianças normais provavel- mente ocorre pela maturação do mecanismo responsável pela conversão dos carotenos em vitamina A. ${ }^{7}$

Não obstante a benignidade do quadro, a sua correta identificação é de extrema importância por forma a evitar a, não tão rara, confusão diagnóstica com icterícia e subsequente estudo desnecessário, dispendioso e gerador de ansiedade.

\section{REFERÊNCIAS BIBLIOGRÁFICAS}

1. Sale TA, Stratman E. Carotenemia associated with green bean ingestion. Pediatr Dermatol. 2004;21(6):657-9.

2. Lascari AD. Carotenemia: a review. Clin Pediatr (Phila). 1981;20(1):259.

3. Christopher R, Rangaswamy GR, Santhoshkumar N, Shetty KT. Carotenoderma in metabolic carotenemia. Indian Pediatr. 1997;34(11): $1032-4$.

4. Schwartz RA, Grzybowski J. Carotenemia. In: Medscape [Internet]; [cited 2017 Apr 11]. Available from: http://emedicine.medscape.com/article/1104368-overview

5. Karthik SV, Campbell-Davidson D, Isherwood D. Carotenemia in infancy and its association with prevalent feeding practices. Pediatr Dermatol. 2006;23(6):571-3.

6. Nishimura T. A correlation between carotenemia and biliary dyskinesia. J Dermatol. 1993;20(5):287-92.

7. Patel H, Dunn HG, Tischer B, McBurney AK, Hach E. Carotenemia in mentally retarded children: I. Incidence and etiology. Can Med Assoc J. 1973; 108(7):848-52.

\section{CONFLITO DE INTERESSES}

Os autores declaram não ter quaisquer conflitos de interesse.

\section{ENDEREÇO PARA CORRESPONDÊNCIA}

Raquel Xavier Martins Costa

E-mail: raquelxaviermartins@gmail.com

https://orcid.org/0000-0002-9671-6737

Recebido em 12-12-2017

Aceite para publicação em 28-04-2019 


\section{ABSTRACT}

\section{WHEN VEGETABLES ARE TOO MUCH: A CASE OF CAROTENODERMIA}

Introduction: Carotenes are a ubiquitous pigment in nature, initially identified in carrot. Ten percent of the ingested pigment is absorbed unchanged and transported to the liver. The remainder is converted, in the intestine itself, into vitamin A. The excess is excreted by the colon and epidermis. However, when its ingestion is elevated, the fat-soluble stratum corneum reabsorbs it and accumulates it, giving a yellowish color to the skin. Children, either due to the immaturity of the enzyme conversion systems or due to the diet and food preparation mode, are more likely to show high levels of carotene in the blood (carotenemia) and on the skin (carotenodermia).

Case Report: G.A.F., male, is brought to the 9-month surveillance counsel. He shows a yellowish color of the palms and plants, without any other complaints or intercurrences. On examination, sclera and oral mucosa show normal staining. His mother reports excessive consumption of carrots and sweet potatoes in the soup. It is considered to be carotenodermia and parents are explained the benignity of the situation and advised to reduce the intake of those foods.

Comment: Although other causes besides diet are extremely rare in children, there is an association between carotenemia and several pathologies, namely diabetes mellitus, hypothyroidism, anorexia nervosa, and biliary dyskinesia, which will have to be investigated if dietary changes do not resolve the clinical condition. Carotenes are present in food as encapsulated crystals. Crushing them breaks the cell membranes and makes them more available for absorption, making infant-based purees more prone to its development. Regardless of color, various foods (e.g. broccoli and green beans) have high levels of carotene and should be taken into account in the clinical interview.

Notwithstanding the benign nature of the clinical condition, its correct identification is of extreme importance in order to avoid the not-so-rare diagnostic confusion with jaundice and subsequent unnecessary and costly investigation.

Keywords: Carotene; $15^{\prime} \beta$ carotene dioxygenase. 